\title{
Aspirations and Expectations of Immigrant and Ethnic Minority Students in Spain
}

\author{
Òscar Prieto-Flores ${ }^{1} \&$ Jordi Feu ${ }^{1}$ \\ ${ }^{1}$ School of Education \& Psychology, University of Girona, Spain \\ Correspondence: Òscar Prieto-Flores, School of Education \& Psychology, University of Girona, 17071, Girona, \\ Spain. Tel: 34-972-410-8987. E-mail: oscar.prieto@udg.edu
}

Received: July 21, 2015 Accepted: August 12, 2015 Online Published: October 20, 2015

doi:10.5539/res.v7n12p121 URL: http://dx.doi.org/10.5539/res.v7n12p121

\begin{abstract}
The expectations held by secondary school teachers play a key role in university access of immigrant and ethnic minority students. Even so, the majority of scientific research conducted in Spain has paid little attention to this, as well as giving little consideration to the exclusive and inclusive dynamics that can occur in secondary schools. When speaking about the educational success of these students, in general, we usually only look at elements relating to the capacities of these young people, endogenous to their own culture or to their socioeconomic environment. Although this last element is important, this study emphasizes the situation of access of these groups in a Spanish university and its area of influence and how the expectations of teachers and of their immediate surroundings are important in shaping the aspirations and expectations of minority students. We also highlight the elements that can contribute to overcoming low educational expectations and facilitate access to the university.
\end{abstract}

Keywords: ethnic minority students, immigration, expectations, higher education, Spain

\section{Introduction}

Spanish society is becoming increasingly heterogeneous by virtue of, among other issues, the wave of immigration that has occurred over the past two decades. In only a short number of years (1998-2010), the foreign population grew from $1.6 \%$ of the total population to $12.1 \%$ (INE, 2010). However, irrespective of this relatively recent phenomenon, Spain has been home to ethnic minorities for many centuries, as is the case of the Romani population. By seeing what the educational experience of this collective has been we can intuit the expectations and educational trajectories that will be followed by students of foreign origin and other ethnic minorities. Nevertheless, beyond the rather bleak verifications, it should be pointed out that there are different actions that may indicate certain changes in this trend and that may emerge as anti-racist actions promoting greater equity and social inclusion.

The objective of this article is to identify, on the one hand, the representation of minority students in a Spanish university and on the other, to analyze how the educational expectations of students of immigrant origin and ethnic minorities, and their immediate educational environment, can define their educational trajectory and access to the university.

To do so, this study analyzes from a qualitative perspective the narratives of minority students currently enrolled in secondary school (Note 1) as well as university students of similar origin. Bearing in mind that the influence of teachers and the institutional dynamics that occur in all processes of educational exclusion/inclusion are relevant, we also interviewed and analyzed the discourse of different professionals connected to this educational stage, principally secondary school teachers.

Although the different tracks in the educational system of the population can be conditioned by the socioeconomic situation of families (Coleman et al., 1966; Bowles \& Gintis, 1976) or by the presence of other significant persons - really significant others - such as family, teachers or peer group (Haller \& Portes, 1973; Portes \& Fernández-Kelly, 2008); various studies have also emphasized how the presence or absence of racial prejudice, or low or high expectations among teachers and other educational agents, can have a negative or positive effect on the achievement level of ethnic minority students (Fergusson, 1998; Flecha, 1999; Sordé, 2006; Ladson-Billings, 2009; Gillborn \& Youdell, 2000). All of these elements, thus, play a decisive role in a large part 
of the processes of educational and social exclusion/inclusion of young people.

Does the Spanish case differ with regard to other national contexts? The hypothesis presented in this work is that, in addition to all the other factors referred to by earlier research in the framework of the Spanish state, which accentuates, above all, the socioeconomic component of these students and their families, as well as the human capital of the same; the existence of prejudices among teachers also has significant importance, as does the perception that the student has respect for the accompaniment offered to them in their educational trajectory in secondary education, whether obligatory or post-obligatory.

How to overcome the prejudices of the community, and in particular of teachers, and how to overcome the solitude and "abandonment" suffered by these young people are challenges that many ethnic minority students must confront, as we will see later, in order to successfully complete secondary school and gain entry to the university.

\section{Theoretical Framework}

\subsection{Aspirations, Expectations and School Success among Minority Students}

Even though the educational expectations of parents (Coleman, 1988; Hao \& Bonstead-Burns, 1998; Goyette \& Xie, 1999) as well as those of the peer group (Duncan, Haller, \& Portes, 1968; Sokatch, 2006) are usually of importance in positively or negatively determining the aspirations of minority students from vulnerable socioeconomic environments, teachers' expectations also have an impact and therefore, must be kept well in mind in sociological analysis. Along these lines, the works of Rosenthal and Jacobson (1968), Brophy and Good (1974) and Rist (2000), are good examples.

When educational expectations and the ethnic and racial origin of students are taken together, various studies have shown that there is a tendency to attribute lesser abilities and competences to certain minority groups. For example, in the United States, Ford and Thomas (1997) observed that representation of minority students in programs designed for academically talented students was $50 \%$ lower than the rest of students. According to these authors, this low representation could be as much as $70 \%$ lower in the case of Afro-American students. This situation, the authors stress, is as much the result of socioeconomic factors specific to these young people and their families as the low expectations that teachers have for minority students.

In Europe similar studies have also been carried out. A very clear case is the low representation of Romani students in ordinary schools in the Czech Republic and, surprisingly, their overrepresentation in special education schools. Cahn and Chirico (1999) verified that the percentage of Romani population in this latter type of school (segregated, obviously) was $62.5 \%$ as compared to only $4.2 \%$ from the rest of the population. As Gillborn $(2010,2004)$ warns, we must be careful in drawing an interpretive explanation from these results because quantitative studies abound that accentuate the skills and competences of minority students, understanding these as a personal quality, and omitting manifest and hidden social processes that exert as much or greater force in the process of discrimination.

In terms of the educational trajectories that minority students tend to follow in secondary school, it has also been verified that the presence of discrimination processes contributes to overrepresentation of minority students in lower level educational tracks (Mickelson, 2001; Strand, 2007). Diverse studies have emphasized the fact that the earlier that tracking is implemented in the education system; more differences are observed in educational results between minority and majority students (INCLUD-ED, 2006-2011). This situation does not occur in a homogeneous way (in the same way nor with the same intensity) in all minority groups: the reality is segmented, affecting some minority groups more than others. For example, teachers' expectations tend to be higher for Asian students than for the rest of students, especially in scientific-technical subjects (Wong, 1980). But we can also find evidence that shows that the same ethnic group may have different educational results depending on the national context. A particular case that exemplifies this situation in Europe is that of second-generation Turkish immigrants in Germany. Crul and Schneider (2010) point out that only 3\% gain entry to the university in comparison with $40 \%$ from the same collective in France or Sweden. The authors conclude that these differences arise, in large measure, because Turkish students in Germany tend to enter very early — at age ten - an educational track with low educational expectations.

On the other hand, however, research exists that points to how these low expectations can be overcome, through strengthening of the support networks or social capital of minority students, to give only a couple of examples. Some of this research has emphasized the presence of a minority culture of mobility among the Afro-American and Hispanic population of the United States, which, the stronger it becomes the greater are the expectations it generates within the community (Neckerman et al., 1999; Kazinitz et al., 2000). This culture, the authors explain, 
has been promoted by minority students who were successful in school and, after overcoming the obstacles of the education system, were elevated to the status of role models in the community. Other research has highlighted the existence of positive socio-psychological dynamics in the classroom (occurring in the framework of the routine interaction between teachers and minority students) that substantially enhances the academic performance of disadvantaged students (Alexander et al., 1987). We also find cases in the scientific literature that demonstrate the power of the presence of minority group teachers in secondary schools in creating a positive effect on the educational experience of these students; in that this presence creates closer and more significant connections as a result of being able to successfully link educational experience with life experience (Warikoo, 2004).

Ricardo (1997) analyses how ethnic minority students find that they must confront and struggle against a context in secondary schools that is often adverse owing to existing reproductive cultural and social forces. To overcome this situation, they must become socialized, "decoding" the language of the power systems of educational institutions, not only with the objective of achieving individual success but also to democratize the system by means of bicultural network orientation through which minority students find support among themselves to be able to confront situations of discrimination or conflict and negotiation with institutional agents (faculty or school administrative team).

From our point of view, both studies that show the obstacles, racial prejudices and low expectations in teacher-minority student relations, as well as those that point out inclusive elements that can eventually overcome these situations, have great scientific and social value.

\subsection{The Spanish Context}

In Spain, there are also studies that have focused on educational failure, trying to grasp dynamics that go beyond that which is related to socioeconomic environment. Even so, there is too much research, such as that conducted by Mora (2010), that hasn't taken cultural elements or institutional or ethnic discrimination into account. Regrettably, there is abundant research that emphasizes, as explicative elements of what concerns us here, the cognitive performance of students, their personality or the characteristics of the educational institution, etc. It is of course true that there are some studies, such as the research by Fernández-Enguita et al. (2010), among others, which indicate that the educational failure of certain groups is the result of the combination of different factors such as rejection of school on the part of students themselves, the activation of privative elements unleashed during the migratory process, the inappropriate use of the language of the host country and the assumed "quality" of the educational system of origin.

Other research more focused on minority students provides, from our point of view, a more complete vision of reality. Portes et al. (2010), for example, observed through the ILSEG survey the determinants that affect the educational aspirations and expectations of these students in Spain. Among these, they emphasized socioeconomic status of the family, the human capital of the same, family composition, place of birth, the type of school they attended and gender. These authors observed that the aspirations and expectations in second-generation immigrants in Spain, specifically in the Madrid sample, are much lower in comparison to results obtained in the United States. Whereas $66.5 \%$ of second generation adolescents in the U.S. aspired to a post-graduate degree and $44 \%$ expected to achieve it (Portes \& Rumbaut, 2001), these figures for the ILSEG Madrid sample are $9.3 \%$ and $5.1 \%$ respectively. They also stress the importance of how "the significant others" can have an influence on these aspirations and expectations, but they only emphasize family members or the student's closest friends. They do not specifically speak about teachers' expectations towards ethnic minority students or about the existence or absence of culturally relevant teaching practices.

The article presented here, drawing from works by Flecha (1999) among others, places emphasis on the need to take into account "silenced" elements that, as the reader will easily deduce, have to do with modern and post-modern racist dynamics among educators as well as practices implemented in educational institutions.

In relation to this perspective, Tomás demonstrated in the 1980s and 90s the high level of prejudice among both teachers and students towards the Romani population. These prejudices sometimes contained "......considerable doses of intolerance and, at times, with a minority but militant racism" (1990, p. 30) that negatively affected the learning process and educational success of Romani students. Along these lines Jesús Gómez and Julio Vargas (2003) affirmed that Romani students didn't like the paia [non-Romani] school because of the explicit and implicit discriminatory attitudes in the school institution and, in addition, because of the low expectations extant among part of the teaching staff. These authors proposed, to counter this situation, educational projects such as learning communities, which foster high expectations among minority students as well as the participation of Romani families in schools. 
The feat of turning the aforementioned situation around is indeed possible and some authors, such as Teresa Sordé (2006), have observed that there is an emerging movement among Romani women that demands that primary and secondary schools promote high expectations towards their daughters, vindicating their Romani identity.

Students of immigrant origin are not exempt from these dynamics that affect the Romani population. Discriminations of all kinds and in the most varied formats, unfounded prejudices among the educational community, and low expectations towards students bar the way in the educational promotion of many students of immigrant origin. Notwithstanding, Paulaudàries and Serra (2010) stressed that there are certain minority groups, among students of immigrant origin, in which the passage from obligatory secondary education to upper secondary school studies is more "problematic". For example, dropping out by students of Gambian, Chinese or Moroccan origin is in contrast with the degree of continuity displayed by Ecuadorians, Romanians or Argentineans.

This article, which uses as its starting point the case analysis of a Spanish university and its most direct area of influence, is organized in the following way. After discussing the methods and techniques employed during the research, we show the representativeness of minority students in the university and then analyze the dynamics of exclusion and inclusion that occur in secondary schools, by examining narratives of both students and teachers. Lastly, we discuss the social and political implications of the results obtained.

\section{Methods and Data}

The data presented in this article corresponds to research whose objective is to quantify the representativeness of minority group students in a university in northeastern Spain (we can call this university Northeast Catalonia University - hereafter NCU) and, in other respects, attempts to explain the dynamics that hinder access of these groups to the university and those that make it possible. We understand minority group students, in this study, as those students who are underrepresented in the university, are usually of foreign origin, who belong to an ethnic minority that has historically been excluded from the institutions of the majority society, or come from a vulnerable socioeconomic family environment. The study took into account these three profiles and the intersections that exist between them.

To record the presence of this type of students in NCU and to frame this in relation to its most direct area of influence, we compared data on the population structure of the territory in question-source: Statistics Institute of Catalonia (2009); with data from NCU (academic year 2009-2010). We paid particular attention, because of the characteristics of the research, to population data segmented by gender, age group and nationality. In this way, when we focused analysis on nationality, we were able to weigh the representation of groups of immigrant origin between 18 and 25 years of age enrolled in undergraduate studies at the university. Using this data we generated an index of representativeness of immigrant students at NCU, adopting as baseline data non-foreign (native) students. This index is expressed in base 100 and is ordered in a table to be able to visualize and objectify the degree of underrepresentation.

We must point out that we met with a certain limitation when searching for quantitative information on some of the socially disadvantaged and educationally underrepresented groups such as, for example, the Romani. The fact that neither municipal registers of inhabitants nor university registers or Catalan or Spanish institutions collect this type of data - something that is done in other countries - makes them, for all intents and purposes, practically invisible. This fact also occurs among the children of immigrants born in Catalonia and who have Spanish nationality (second generation). Thus, the quantitative analysis presented here only reflects the situation of the immigrant population who as young people arrived in Spain with their parents (otherwise known as generation 1.5).

For the collection of quantitative information we conducted twenty-five semi-structured in-depth interviews, the majority of which were carried out employing more of a narrative approach than a conventional directed interview. Independently of this, in all of the cases we employed a previously drawn up script of questions, allowing, however, a large amount of leeway to the person being interviewed, especially when dealing with young people about whom we were most interested in having them explain at length their student experiences and expectations for the future.

The twenty-five interviews that were conducted correspond to different profiles: ten with students of immigrant origin who are enrolled in upper secondary school or intend to do so in order to gain access to the university; five interviews with students of foreign and Romani origin who are studying at the university where the case study was carried out; and ten interviews with secondary school teachers. 
With the objective of selecting the most appropriate profiles and locating the individuals to be interviewed, the research team got in touch with faculty and staff from NCU and various secondary schools. To ensure territorial diversity we chose four secondary schools: two from the same city the university is located in and the remaining two from towns in the area of direct influence, but with different territorial characteristics -one inland and the other coastal.

Lastly, we must emphasize that in both the interview scripts and in their subsequent analysis we not only took into account the excluding factors or the obstacles faced by minority students or students from socioeconomically vulnerable environments in access to the university, but also the transformational dimensions of the critical communicative methodology that, as indicated by Gómez et al. (2006), are those that contribute to overcoming obstacles that prevent the inclusion of excluded individuals and/or groups in social practices, institutions or benefits.

\section{Results and Analysis}

\subsection{Representativeness of Minority Students at NCU}

Over the past twenty years the most direct area of influence of NCU has incorporated a large number of people coming from different countries. This process, common in all advanced societies, represents an important challenge for local, regional and provincial institutions - as the case may be - in order to promote social inclusion and cohesion. To identify the degree to which institutions incorporate the foreign population, we carried out a comparison of the population structure of Girona and of NCU students between the ages of 18 and 25. In Graph 1 we can observe that the foreign population in this age group in the districts of Girona is quite significant: $32.8 \%$ of young people between the ages of 18 and 25 are of foreign origin and a significant part are of extra-community origin (25\%). Nevertheless, when the representativeness of this group is transferred to NCU, the percentage falls sharply: in the academic year $2009-2010$ only $3.6 \%$ of students are of foreign origin and $2.5 \%$ are extra-community.

Regarding the distribution of the young population of foreign origin broken down into their different origins, the data reveals the hegemony of the African collective, which accounts for $12.7 \%$ of the aggregate population, followed by young people from the rest of the EU (7.8\%), South America (5.9\%), with the remaining groups following at a great distance. However, what is corroborated by the data and is clearly reflected in the following graph, is the scarce university representativeness of each group with the virtual invisibility of the most numerous minority group, which as we stated is the African.

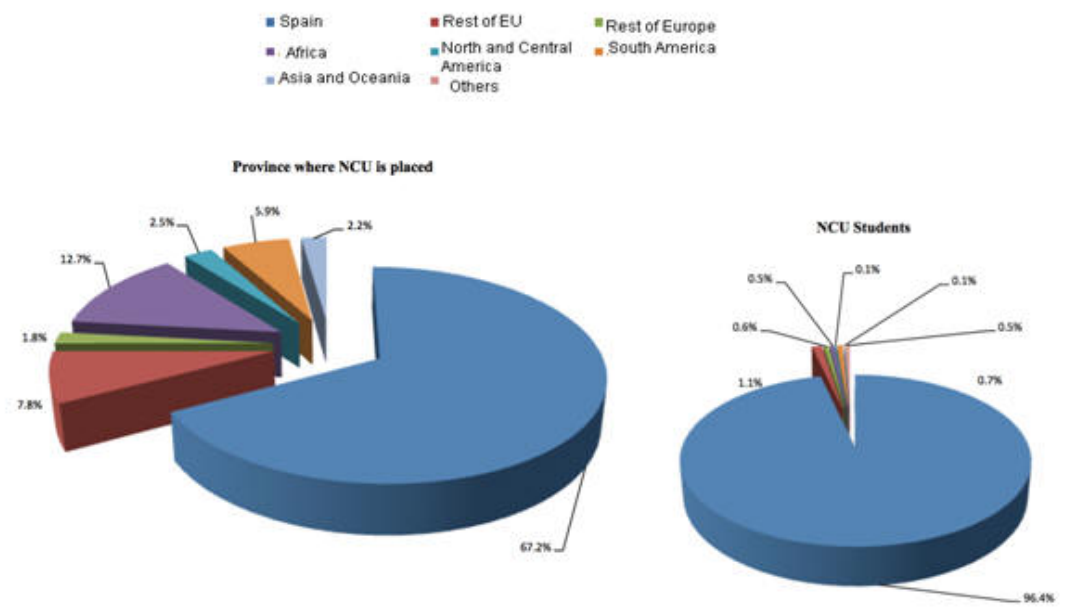

Figure 1. Percentage of the population in the region where NCU is placed and of the NCU, between 18 and 25 years of age by nationality

To correctly and accurately express the representativeness of each group in the university we created an index expressed in the following table. This, besides showing the low representativeness of the generation 1.5, allowed us to establish a hierarchy that reveals the groups that suffer most from exclusion. Our results show that the most 
excluded group in the university system in the region of NCU is, as we indicated earlier, the African (96\%) followed by the Asian (95\%) and the Latin American (95.5\% and 91.5\%).

Table 1. Representativeness index of students of immigrant origin at the NCU by nationality (Population between 18 and 25 years of age)

\begin{tabular}{lll}
\hline Nationality & $\begin{array}{l}\text { Index } \\
\text { (base 100) }\end{array}$ & Index \\
\hline Rest of Europe (note) & 33 & $-67 \%$ \\
Rest of UE27 & 14 & $-86 \%$ \\
South America & 8.5 & $-91.5 \%$ \\
North and Central America & 4.5 & $-95.5 \%$ \\
Asia and Oceania & 4.5 & $-95.5 \%$ \\
Africa & 4 & $-96 \%$ \\
\hline
\end{tabular}

Source: Authors' elaboration from data taken from IDESCAT (2009) and from data of the office of planning and evaluation of the NCU (academic year 2009-2010).

It appears, then, that there is a certain hierarchy in terms of access to the university depending on the group of reference. In interpretation of this data we must avoid incurring in affirmations, inasmuch as this ranking could correspond to a black/white bipolar model. In the European context, and more specifically in the context of NCU, there are groups, such as the Arab-Muslim or Romani, which find themselves in a situation similar to the Sub-Saharan African population, for example. In this way, even though the white/non-white racial hierarchy is obvious, this doesn't correspond to a bipolar model but rather a segmented one in that, as indicated by Gold (2004), the bipolar model is limited in terms of including the diversity and complexity of certain multi-ethnic societies.

Which dynamics hinder the access of these groups to the university and which promote it? The narratives of secondary school students and teachers in addition to those of students of immigrant and Romani origin at NCU provide us with some indications regarding the importance of expectations and support networks.

\subsection{Obstacles to University Access Faced by Minority Students}

In the course of the interviews we identified discriminatory factors that negatively influence minority group students, both in terms of the effect they have on the individual (self-esteem, consideration, self-worth, etc.) and the repercussions they have on their aspirations and educational expectations. To this effect, we identified the relevance taken on by the prejudices and stereotypes of the host society and how this is reflected in primary and secondary schools and in exclusive practices. Some interviewees emphasized the weight of these prejudices in connection with the possibility of continuing with their studies. Mohamed is an upper secondary school student of Maghrebi origin. He explained to us that, throughout secondary school, the prejudices that he has been subjected to because of his condition of being a foreigner have, on more than one occasion, caused him to experience feelings of inferiority and a series of contradictions that were difficult to integrate. Despite the fact that he wanted to continue his studies and attend the university, the discourse he heard, according to his memory and his perception, was that "...foreigners don't have to study and in many aspects they are inferior". He remembers having experienced a visible and explicit stigmatization simply because he belonged to a foreign group. During the obligatory secondary school stage he had to fight, and very hard, against the widely held opinion of teachers in order reach upper secondary school. "They told me I was worthless, that I shouldn't even bother trying."

The expectations created around a group, tied to stereotypes and to the construction of a collective ideology, propitiate the reproduction of diverse dynamics and patterns that perpetuate specific situations. This fact applied to the educational world, and more specifically to students from the most disadvantaged groups, makes access to the university difficult as well as their subsequent continuance once there. To this effect, the expectations that teachers instil in students from disadvantaged groups do indeed matter from the moment these children enter the education system until they leave it. Stated in other terms: the Pygmalion effect is of vital importance: what a teacher thinks about their primary school student carries a lot of weight in facilitating their passage to obligatory 
secondary school; and what a teacher might think about them in this stage, will be one more element that intervenes in their decision of what to do about upper secondary school... and so on successively, right up to the university. These processes, as highlighted in the theoretical framework, have not been taken much into account in the Spanish context, especially in relation to students of immigrant origin. The fact that the educational expectations of generation 1.5 are lower in the Spanish context, as indicated by Portes et al. (2010), has to do with discriminatory processes shaped in the shelter of a dynamic that is prevalent among certain teachers, and that eventually becomes institutionalized. It is important, then, to bear these elements in mind when analyzing school success and failure of minority students and their access to the university.

What, though, are the elements that have a bearing on teachers when they "anufacture"expectations for their students? There are several intervening factors that, often, go beyond strictly academic ones: the student's conduct, ability to internalize and reproduce assigned roles, submissiveness, acquisition of established codes, etc. Within the body of teaching professionals, however, another element becomes evident: it is believed that minority group students will follow one or another track in function of their origin. This is believed to be so, because it is considered-blindly and almost as if it is taken for granted:

a) That there are cultural traditions that place great value on education, and in particular on university studies, while others barely acknowledge any worth at all.

b) Because it is believed that they came here to work and not to study and, for this reason "they don't give any importance to education".

c) Emphasis is placed on a meritocratic system based on assumed abilities of each student and that selects "the best ones".

The interrelation between these factors promotes, as we will see below, that the fact that being a foreigner or member of an ethnic minority — as in the case of the Romani-is almost automatically associated with giving little value to education, being motivated to rapidly enter the labour market and having low ability.

a) Little value in education. In relation to this first element it was stressed in the different narratives of minority students how among teachers some groups are commonly identified (such as Moroccans or Romani) as groups that give little value to education. One student who is currently at the university stated the following: "...when I was in the 3rd year of ESO [Obligatory Secondary Education] the math teacher told me that I wouldn't make it to upper secondary school because I was Moroccan. But see, not only did I make it through upper secondary school but now I'm at the university.....I'm lucky I didn't believe her!".

b) Motivation to rapidly enter the labour market. Most of the persons interviewed, both students of foreign origin and teachers, coincide in affirming that there is a widespread social opinion that foreigners don't continue with their studies because they come here with the goal of finding work and earning money. Three of the teachers interviewed (Carme, Marc \& Cristina) coincide in emphasizing that right from the beginning, in primary school, dynamics and practices are generated that are related to this question. From the time they are small children, then, from all sides they are bombarded with the same message ".....their only possible itinerary is to enter the work world and in the event they display interest and the capacity to study, they are indirectly guided towards vocational training".

c) Low abilities. In this research we were able to identify the existence of a hegemonic discourse in secondary education based on the individual merits of each student. This discourse promotes a meritocratic system that does not take into consideration individual situations and much less the situations of disadvantage in which many students find themselves. The orientation and expectations of all educational agents, especially in the late stage of ESO, are paramount in facilitating continuation in upper secondary school studies, which in turn provide access to the university. Likewise, all of the reinforcement that can be given in school during these stages is very important, especially if the student shows interest — even if minimally — in the education system.

Antoni, a teacher in upper secondary education at an IES [public secondary school] with a tradition in these types of studies, expresses his opinion on the low representativeness of students from disadvantaged groups in this educational phase: “...students' capacities are decisive in guaranteeing success in upper secondary school; many students of foreign origin neither have these capacities nor demonstrate the will to achieve them; they have other interests. So, it's quite normal that they don't make it this far".

Antoni puts his faith in an education system based exclusively on merits, and with the information drawn from the interview we were able to perceive a very superficial analysis of the factors that can make it difficult for certain groups to successfully progress through the education system. This very restrictive version was, by contrast, opportunely qualified by students who had indeed made it to upper secondary school, despite facing 
many obstacles: “...I was finally able to make it to upper secondary school, but with a lot of effort......I didn't only have to make the effort because I had to study more, because all in all it was really hard, etc., but also because unlike ESO you don't normally get much support from teachers".

Mohamed recalls a bitter and harsh memory, a reflection of how the expectations that teachers hold for students are institutionalized in different educational tracks. "...the majority of teachers treated me as if I was inferior and didn't have enough ability. Belonging to the curricular adaptation unit (group E) attached a stigma to me that hindered the relation with classmates and with teachers. Group E demonstrated the low expectations of teachers with regard to my academic ability. It gave me the feeling that I was in this group because I belong to a certain [minority] group and not because of my abilities. When I requested a change of level and showed interest they treated me like I was a nuisance and wouldn't let me enrol in upper secondary school. Only a few teachers, who were only temporarily in the school, had confidence in my abilities and potential. In order to change groups I had to look for outside support and prove that I could advance”.

\subsection{Overcoming Obstacles to University Access}

Help, support, perseverance and determination are elements that significantly aid progress in the education system. Through the interviews conducted we were able to confirm that even students who despite having learning difficulties and only mediocre academic records, ended up going to the university if they were able to meet someone along the way to help and support them.

In the abstract we explained in sufficient detail how there are schools that propitiate students' progress in the education system while others do just the opposite. And this does not only occur because in some schools there are teachers that encourage and generate positive expectations in their students, or because there is an accelerated curriculum or because a large portion of schoolwork is based on collaborative work.

Jennifer (Romani student at the university) and Cristina (teacher in a secondary school with a strong presence of minority groups) bring to light the problem that exists in the city where NCU is located; stressing the fact that "ghettoization" is an aspect that makes access to upper secondary school studies difficult. In this sector of the city there are two primary schools; and both the teacher and the student are of the opinion that educational reform and structural change are needed in order to modify current dynamics that, most assuredly, contribute to the fact that students from these schools don't advance, educationally speaking. Even though these two individuals coincide in their diagnoses, they differ when it comes to considering how this can be overcome. Jennifer believes that "...it would be a positive thing to have a primary school and an IES in the neighbourhood that promote the educational success and good results of students so as to generate territorial continuity and facilitate kids'sense of belonging to the community".

On the contrary, Cristina is of the opinion that "...this option would ghettoize the neighbourhood even more and I believe that it's necessary to have a good distribution of students in the different schools in the municipality, in order to avoid the current problems of relation and school failure suffered by these students, especially in the transition from primary to secondary school".

Although Jennifer's proposal to promote magnet schools and improvements in the neighbourhood is endorsed by an important part of the international scientific community (Frankenberg \& Siegel-Hawley, 2008), Cristina's idea is more than questionable. For quite some time evidence has been furnished showing that this type of policy doesn't contribute significantly to the educational improvement of minority groups (Orfield, 1978), even though in Spain mandatory redistribution only for immigrant and minority students is one of the main strategies that has been implemented. Jennifer tells us that her family, given the low level of learning of the students in this school, has chosen to enrol their younger children in primary schools outside the neighbourhood.

Many students of foreign origin consider, taking their experiences into account, that a good inclusive and facilitating strategy for school success is, above all in the phase of primary and secondary school, a learning system based on cooperative work, dialogic learning and high expectations (Flecha 1999): “.... with this system, it made us feel that we weren't excluded, and if we fell behind in something, we easily caught up thanks to the help from our classmates. Furthermore, in the group everyone was able to contribute their best.... and this made you feel good". They regret that these work dynamics are too sporadic and don't have continuity in the schools "...it's like everything depends on what teachers want".

Omar, a university student of foreign origin, proposes improvements in the relations between teachers and families with the objective of propitiating (through prior work) the educational aspirations and expectations of both families and teachers. He explains that, "...families, at times, are stuck in a very simple idea and if they were made to participate more, they would surely be able to take greater advantage. It would be very enriching for 
families to understand the actual function of the programs that improve expectations and make them accomplices in a joint educational enterprise between teachers and families".

Many young people insisted on the need to implement mechanisms that would allow students, especially new ones, to be able to count on a peer group with which they could share common interests and educational tracks, and which could facilitate emotional and socio-affective accompaniment in the different stages of the education system: “...upper secondary school is very difficult and to study and relate with students who pay attention to you and with whom you can share things both in and outside of school makes everything easier, even the workload", Marc tells us. Valeria explained that the opportunity of having a linguistic partner was a big help to her in school and that it's a shame that this experience can't be more widespread: “....thanks to this partner, I was able to make friends when I got here, I learned Catalan and I felt supported by friends I was able to trust".

In another order of questions, and in a more organizational sphere, there were those who greatly valued the individualized attention in many specific aspects on the part of competent professionals. Jennifer, in the semi-private secondary school (Note 2) where she received her schooling, had a classroom tutor and a personal tutor who provided close and personal monitoring, and this helped her to form trusting relationships that brought about very positive results. Other students who made similar points demand the generalization, both in primary and secondary school, of programs entrusted to competent professionals working in an integrated way, with high expectations, with students, teachers, schools, peer group and family. The objective, besides what was cited previously, is to create synergies and shared responsibilities among different agents, especially among teachers.

\section{Conclusions}

Although there are structural elements that we must bear in mind to overcome poverty and the situation of inequality of certain groups; cultural elements (Wilson, 2010), aspirations and expectations, and interactions between teachers and minority students also play an important role in defining educational trajectories, especially in the secondary school stage.

The case study we analyzed, that of NCU and its most direct territory of influence, confirms the very low presence at the university of students of immigrant origin (generation 1.5) and of ethnic minorities. Here are the most relevant data concerning the reality under study: in the area of influence of NCU, while the foreign population between 18 and 25 years of age is $32.8 \%$; the representation of this population at NCU is only $3.5 \%$. This situation is made even worse if the students' origin is taken into account. For example, according to the representativeness index of students of foreign origin at the university, students of African origin are those with the greatest difficulties in terms of access to the university, followed by students from Asia and Latin America.

Beyond the cold objective data, however, what are the factors - above all for students of foreign origin and ethnic minorities - that hinder access to Spanish universities and in particular to NCU? Using the obtained narratives as our starting point we were able to identify as a serious restraint the presence of limiting stereotypes among secondary school teachers, specifically stereotypes that associate specific groups with "....placing little importance or value on education", "a high motivation to rapidly enter the labour market" and also with "having low intellectual capacity". This reality highlights the fact that quantitative studies or analyses conducted thus far regarding the Spanish case must pay greater attention to these dynamics. Palaudàries and Serra (2010) made reference to the existence of these possible exclusive dynamics in secondary schools in an earlier study, pointing out the need to go into greater depth on the subject; Portes et al. (2010) emphasize that the aspirations and expectations of students and their environment are one of the most important predictors of educational success, although they don't enter into an analysis of how these may or may not occur in the Spanish context. In the Romani case, Sordé (2006) and Vargas and Gómez (2003) already corroborated these exclusive and inclusive dynamics; but such an explicit reference in relation to the population of immigrant origin hadn't been expressed until now.

This reality also presents us with new questions for possible future research. In other national contexts, do minority students have greater access to institutions of higher learning than in the Spanish case? If this is so, do we find similar or different processes of discrimination or inclusion of minority students in the university?

In recent years, some outreach experiences have been created in certain Spanish universities-such as the program "Únete" at the University of Almeria or the program Nightingale at the University of Girona-focused on secondary school teachers as well as families. These universities, through the aforementioned programs, contribute to a more inclusive educational process and, in the future, to guaranteeing access to the university. These practices, together with others that promote high expectations among students and good educational results, will most assuredly promote greater equity in our institutions. 


\section{Acknowledgements}

The authors wish to express their thanks for the economic and logistic support they received from the University in the development of the diagnosis. Thanks also to Xavier Besalú, Anna Horno, Sònia Vila, Maria Rosa Tarradellas and Anna Maria Geli for their support and feedback during elaboration of this study.

\section{References}

Alexander, K. L., Entwisle, D. R., \& Thompson, M. S. (1987). School Performance, Status Relations, and the Structure of Sentiment: Bringing the Teacher Back. American Sociological Review, 52(5), 665-682.

Bowles, S., \& Gintis, H. (1976). Schooling in Capitalist America: Educational Reform and Contradictions of Economic Life. New York: Basic Books.

Brophy, J., \& Thomas, L. (1974). Teacher-Student Relationships: Causes and Consequences. New York: Holt.

Cahn, J., \& Chirico, D. (1999). A Special Remedy: Roma and Schools for the Mentally Handicapped in the Czech Republic. Budapest: European Roma Rights Center.

Coleman, J. S., Campbell, E., Hobson, C., McPartland, A., Mood, A., Weinfeld, F., \& York, R. (1966). Equality of Educational Opportunity. Washington, DC: United States Department of Education.

Coleman, J. S. (1988). Social Capital in the Creation of Human Capital. American Journal of Sociology, 94, 95-120.

Crul, M., \& Schneider, J. (2010). Comparative integration context theory: Participation and belonging in new diverse European cities. Ethnic and Racial Studies, 33(7), 1249-1268. http://dx.doi.org/10.1080/01419871003624068

Duncan, O. D., Haller, A. O., \& Portes, A. (1968). Peer Influences on Aspirations: A Reinterpretation. American Journal of Sociology, 74(2), 119-137. http://dx.doi.org/10.1086/224615

Fergusson, R. (1988). Teachers' Perceptions and Expectations and the Black-White Test Score Gap. In Ch. Jencks, \& M. Phillips (Eds.), The Black-White Test Score Gap (pp. 273-318). Washington, DC: Brookings.

Fernández-Enguita, M., Mena, L., \& Riviere, J. (2010). Fracaso y abandono escolar en España. Colección Estudios Sociales, 29.

Flecha, R. (1999). Modern and Postmodern Racism in Europe: Dialogic Approach and Anti-Racist Pedagogies. Harvard Educational Review, 69(2), 150-172. http://dx.doi.org/10.17763/haer.69.2.3346055q431g2u03

Ford, D., \& Thomas, A. (1997). Underachievement Among Gifted Minority Students: Problems and Promises. ERIC Digest E544, available in ERIC.

Frankenberg, E., \& Siegle-Hawley, G. (2008). The forgotten choice? Rethinking magnet schools in a changing landscape. A report to Magnet Schools of America. UCLA: The Civil Rights Project.

Gillborn, D. (2004). Ability, selection and institutional racism in schools. In M. Olssen (Ed.), Culture and learning: Access and opportunity in the classroom (pp. 279-297). Greenwich: Information age.

Gillborn, D. (2010). The colour of numbers: Surveys, statistics and deficit-thinking about race and class. Journal of Education Policy, 25(2), 253-276. http://dx.doi.org/10.1080/02680930903460740

Gillborn, D., \& Youdell, D. (2000). Rationing education: Policy, practice, reform and equity. Buckingham: Open University Press.

Gold, S. J. (2004). From Jim Crow to racial hegemony: Evolving explanations of racial hierarchy. Ethnic and Racial Studies, 27(6), 951-968. http://dx.doi.org/10.1080/0141987042000268549

Goyette, K., \& Xie, Y. (1999). Educational expectations of Asian-American youth: Determinants and ethnic differences. Sociology of Education, 71(2), 24-38. http://dx.doi.org/10.2307/2673184

Haller, A., \& Portes, A. (1973). Status Attainment Processes. Sociology of Education, 46, 51-91.

Hao, L., \& Bonstead-Bruns, M. (1998). Parent-Child Differences in Educational Expectations and the Academic Achievement of Immigrant and Native Students. Sociology of Education, 71(3), 175-198. http://dx.doi.org/10.2307/2673201

INCLUD-ED. (2006-2011). Strategies for Inclusion and Social Cohesion in Europe from Education. An Integrated Project of the Sixth Framework Research Programme of the European Commission. Brussels: European Commission. 
INE. (2010). Datos del padrón municipal. Madrid: Instituto Nacional de Estadística.

Kazinitz, P., Battle, J., \& Miyares, I. (2000). Fade to Black? The Children of West Indian Immigrants in Southern Florida. In A. Portes, \& R. G. Rumbaut (Eds.), Ethnicities. Children of Immigrants in America (pp. 267-300). Berkeley and New York: University of California and Russell Sage Foundation.

Ladson-Billings, G. (2009). The dreamkeepers. Successful teachers of African American children (2nd ed.). San Francisco: Jossey Bass.

Levin, H. (1990). The Educationally Disadvantaged Are Still Among Us. In J. G. Bain, \& J. L. Herman (Eds.), Making Schools Work for Underachieving Minority Students. Next Steps for Research, Policy and Practice (pp. 3-12). Westport: Greenwood Press.

Mickelson, R. A. (2001). Subverting Swann: First- and Second-Generation Segregation in the Charlotte-Mecklenburg Schools. The American Educational Research Journal, 38(2), 215-252. http://dx.doi.org/10.3102/00028312038002215

Mora Corral, J. A. (2010). Determinantes del abandono escolar en Cataluña: más allá del nivel socio-económico de las familias. Revista de Educación, Special Issue, 171-190.

Neckerman, K. M., Carter, P., \& Lee, J. (2003). Black American students in an affluent suburb: A study of academic disengagement. New Jersey: Lawrence Erlbaum.

Neckerman, K. M., Carter, P., \& Lee, J. (1999). Segmented assimilation and minority cultures of mobility. Ethnic and Racial Studies, 22(6), 945-965. http://dx.doi.org/10.1080/014198799329198

Orfield, G. (1978) Must We Bus? Segregated Schools and National Policy. Washington, DC: The Brookings Institution.

Palaudàries, J. M., \& Serra, C. (2010). Deficiencias en el seguimiento del abandono escolar y trayectorias de continuidad del alumnado de origen inmigrado. Revista de Educación, Special Issue, 283-305.

Portes, A., Aparicio, R., Haller, W., \& Vickstrom, E. (2010). Moving Ahead in Madrid: Aspirations and Expectations in the Spanish Second Generation. International Migration Review, 44(4), 767-801. http://dx.doi.org/10.1111/j.1747-7379.2010.00825.x

Portes, A., \& Fernández-Kelly, P. (2008). No Margin for Error: Educational and Occupational Achievement among Disadvantaged Children of Immigrants. The ANNALS of the American Academy of Political and Social Science, 620(1), 12-36. http://dx.doi.org/10.1177/0002716208322577

Rist, R. C. (2000). HER Classic: Student Social Class and Teacher Expectations: The Self-Fulfilling Prophecy in Ghetto Education. Harvard Educational Review, 70(3), 257-301. http://dx.doi.org/10.17763/haer.70.3.1k062416102u2725

Rosenthal, R., \& Jacobson, L. (2003). Pygmalion in the Classroom. In Teachers' expectations and pupils' intellectual development. Norwalk: Crown House Publishing.

Smith, H. (2007). Playing a different game: The contextualised decision-making processes of minority ethnic students in choosing a higher education institution. Race, Ethnicity and Education, 10(4), 415-437. http://dx.doi.org/10.1080/13613320701658456

Sockatch, A. (2006) Peer Influences on the College-Going Decisions of Low Socioeconomic Status Urban Youth. Education and Urban Society, 39, 128-146.

Sordé, T. (2006). Les reivindicacions educatives de la dona gitana. Barcelona: Galerada.

Stanton-Salazar, R. D. (1997). A Social Capital Framework for Understanding the Socialization of Racial Minority Children and Youths. Harvard Educational Review, 67(1), 1-41. http://dx.doi.org/10.17763/haer.67.1.140676g74018u73k

Strand, S. (2007). Minority Ethnic Pupils in the Longitudinal Study of Young People in England (LSYPE). Report of the Department for Children, Schools and Families of the United Kingdom.

Vargas, J., \& Gómez, J. (2003). Why Romà do not like mainstream schools: Voices of a people without territory. Harvard Educational Review, 73(4), 559-590. http://dx.doi.org/10.17763/haer.73.4.k6807432592612j3

Warikoo, N. (2004). Race and the teacher-student relationship: Interpersonal connections between West Indian students and their teachers in a New York City high school. Race, Ethnicity and Education, 7(2), 135-147. http://dx.doi.org/10.1080/1361332042000234268

Wilson, W. J. (2010). Why Both Social Structure and Culture Matter in a Holistic Analysis of Inner-City Poverty. 
The ANNALS of the American Academy of Political and Social Science, 629(1), 200-219. http://dx.doi.org/10.1177/0002716209357403

Wong, M. (1980). Model Students? Teachers' Perceptions and Expectations of Their Asian and White Students. Sociology of Education, 53(4), 236-246. http://dx.doi.org/10.2307/2112532

\section{Notes}

Note 1. In Spain, the secondary school stage is divided into two sub-stages: a) obligatory secondary education (ESO) from 12 to 16 years of age, and post-obligatory or upper secondary school from 17 to 19 years of age, as the case may be. This second stage has two branches: pre-university studies that lead to the university; and mid or higher level professional or vocational training that, by passing a preliminary exam, also grants students access to the university.

Note 2. We are referring to state-assisted private secondary schools maintained by public funds.

\section{Copyrights}

Copyright for this article is retained by the author(s), with first publication rights granted to the journal.

This is an open-access article distributed under the terms and conditions of the Creative Commons Attribution license (http://creativecommons.org/licenses/by/3.0/). 